\title{
The residential selection based on fuzzy multi-objective decision
}

\author{
Lin Zhang, Ke Wu, Di Xia \\ College of Mathematics and Information Science, Nan Chang Hang Kong University, 330063, Nan \\ Chang, Jiangxi, China
}

zhjiaoxue@163.com,wwkkdl@163.com, 1017112852@qq.com

\begin{abstract}
Keywords: Transportation Engineering; fuzzy multi-objective; membership functions; Borda function; fuzzy nearness
\end{abstract}

Abstract. In order to explore the process of residential selection, the fuzzy closeness degree of the interaction between the residential area and the target of location were proposed by the fuzzy quantitative treatment of all targets of location. According to the semantic evaluation of family satisfaction in each target, the fuzzy nearness degree matrix that community meets all the targets was established by the satisfaction. After the fuzzy comprehensive weights were proposed by the fuzzy ranking model, the highest satisfaction residence in the decision makers' heart was got by Borda functions. Examples show that: the residents from 23 to 30 years old will be as far as possible to select those districts that close to the destination and have lower prices, better entertainment environment. Residents with lower income from 31 to 45 years old will choose districts that have good education environment and lower prices. Low income residents from 46 to 59 years old, usually tend to choose those close to the destination, have lower prices, and close to the park, and have good natural and humanistic greening environment.

\section{Introduction}

With the rapid growth of China's economy and the accelerating process of urbanization, the constructing of a rational and sustainable development of urban traffic and the coordinated development of land use are becoming the focus on every urban planning. The types of land-use include industrial land, commercial land and residential land. Among them, the residential land is not only a large proportion of the total land use in the city, the intensity and efficiency when using land directly affect the overall amount of urban land. Therefore, it is an important basis for making the urban land-use policy to explore the process of residential selection.

At home and abroad, many experts and scholars have made a deeply study on the choice of residential location, and put forward different models. The space model proposed by Hansen and Lowry was distributed the residence by the gravity or entropy model [1]. Its advantage is that the application is simple, but the results cannot show the thought process of the residential selection well. A mathematical programming model [2] was designed to generate the optimal location of the family. The land-use system is composed of many subsystems, whose boundary is fuzzy, the logical relationship is complex. It is difficult to deal with the internal and external logic relations of the system through a mathematical programming model, the reliability of the results is reduced. The relationship between land use and transportation are revealed by the random utility model [3], and a lot of location indicators were used to describe the location characteristics, and it also reflects the behavior of individual decision-making process. However, the majority of those models using observation values extrapolated to reflect the relationship between transportation and land use, it existed model user's preference in data selection, and the selection and processing of index set may also have different degree of arbitrary.

This paper based on the fuzzy mathematics, combined the uncertain factors with the determined data, established the fuzzy multi-objective decision model, and analyzed the satisfaction of each residence, to explain the details of the behavior that the family decision makers choose the residence. 


\section{The fuzzy nearness and fuzzy weight}

During the study period, there are many families who need house-moving in a city, which form set $F$. Suppose that a city has a number of residential areas whose set is $D=\left\{d_{1}, d_{2}, \mathrm{~K} d_{n}\right\}$ and whose sum is $n$.When choosing where to live, any family $j \in F$ has some goals, such as convenient transportation, beautiful environment, complete facilities, good education and medical, good public security in surrounding areas and so on. Suppose that set $M_{j}=\left\{m_{1}^{j}, m_{2}^{j}, \mathrm{~L}, m_{s}^{j}\right\}$ represents the set of family housing targets, where $s$ is the target sum of the family $j$.

In reality, every family has a satisfaction evaluation about each goal of $M^{J}$. However, it's difficult to quantify these evaluations. Here we use fuzzy mathematics to process these semantic items. Let the extent that the residential area $d_{i}$ to meet the target $m_{q}^{j}$ of family $j$ is a fuzzy quantity, denoting as $\tilde{a}_{\mathscr{q} i}^{j}$.The $\tilde{a}_{q i}^{j}$ here means the close degree of which meets the goal $m_{q}^{j}$. So the close degree that residential area $d_{i}$ to meet all targets which in the set $M_{j}$ form the vector $\left(\tilde{a}_{1 i}^{j}, \tilde{a}_{2 i}^{j}, \cdots \tilde{a}_{s i}^{j}\right)$, denoted as:

$$
\tilde{a}_{i}^{j}=\left(\tilde{a}_{1 i}^{j}, \tilde{a}_{2 i}^{j}, \cdots \tilde{a}_{s i}^{j}\right)^{T} .
$$

Among that: ${ }^{\tilde{a}_{i}^{j}}$ represents the close degree that residential area $d_{i}$ to meet all targets. Therefore, the close degree that all community in set $D$ to meet all targets of family $j$ is formed a fuzzy degree matrix $\tilde{A}^{j}$, denoted as:

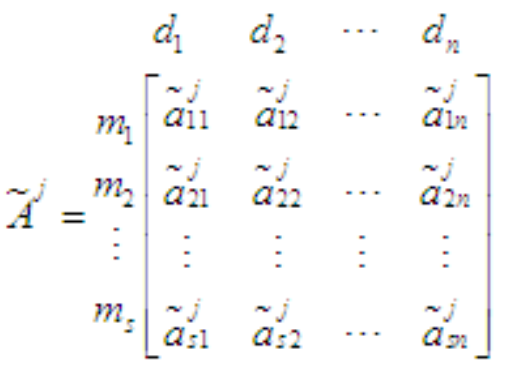

(1)

Here, ${ }^{\tilde{a}_{q}^{j}}=\left(\tilde{a}_{q 1}^{j}, \tilde{a}_{q 2}^{j}, \cdots \tilde{a}_{\varphi n}^{j}\right)$ represents the close degree of $n$ communities to meet the $j$ family's $q$ goal.

To give different weights according to the family's own characteristics in the process of choosing a place to live, here we introduce a weight vector. And denote the weight vector of Family $j$ 's $s$ goals as: $\widetilde{w}^{j}=\left(\widetilde{w_{1}}, \widetilde{w_{2}}, \cdots \widetilde{w}_{s}\right)^{T}$, where the $\widetilde{w}_{q}$ is the weight of the Family $j$ for the goal $q, q=1,2, \mathrm{~L} s$, and all $\stackrel{\sim}{w_{q}}$ are fuzzy numbers.

\section{The fuzzy membership functions}

Due to $\tilde{a}^{j}$ and ${ }^{\simeq}{ }^{j}$ are fuzzy numbers, should not be compared directly to each other. We determine the alternate residential quarters by the fuzzy optimum seeking method. People choose where to live with some goals and expectations, every family has his expectations for each goal. Denote the fuzzy membership function of the location target $m_{q}^{j}$ as: 


$$
u_{\substack{q_{q i} \\ \text { (a) }}}(x)= \begin{cases}\frac{x-l_{q i}^{j}}{n_{q i}^{j}-l_{q i}^{j}} & x \in\left[l_{q i}^{j}, n_{q i}^{j}\right] \\ \frac{v_{q i}^{j}-x}{v_{q i}^{j}-n_{q i}^{j}} & x \in\left(n_{q i}^{j}, v_{q i}^{j}\right] \\ 0 & x \in\left(-\infty, l_{q i}^{j}\right) \cup\left(v_{q i}^{j},+\infty\right)\end{cases}
$$

Set $\stackrel{\mathrm{o}_{a i}^{j}}{{ }_{q i}}=\left(l_{q i}^{j}, n_{q i}^{j}, v_{q i}^{j}\right)$. Where $l_{q i}^{j}$ is the lower bounds value that the decision maker evaluates the close degree. And, $n_{q i}^{j}$ is the expectations value, $v_{q i}^{j}$ is the upper bounds value. In the same way, denote the fuzzy membership function of weight ${ }^{\simeq w_{q}}$ of the target $m_{q}^{j}$ as: ${ }^{\simeq j}=\left(l_{q}^{j}, n_{q}^{j}, v_{q}^{j}\right)$, where $l_{q}^{j}$ is the lower bounds value, $n_{q}^{j}$ is the expectations value and $v_{q}^{j}$ is the upper bounds value of the weight ${\widetilde{w_{q}}}^{j}$.

\section{The optimal fuzzy decision model}

Assuming that similar properties family choose the same level of housing, and there is no cross when different kinds of families to choose the housing. In the same attribute decision-making group of the family, in terms of the target $m_{q}^{j}$, decision makers have a position in their mind for each residence, let $h(h=1,2, \mathrm{~L} n)$ represents the position of residence in the heart of decision makers. According to the fuzzy degree matrix $\tilde{A}^{j}$, if policymakers think the community $d_{r}$ should be in the $k$ place, and $h=k$, then $\operatorname{let} \varphi_{r h q}^{j}=1$, or $\varphi_{r h q}^{j}=0$. Therefore, the ranking matrix of residence that family $j$ for the $\operatorname{target} m_{q}^{j}$ is $\Gamma_{q}^{j}=\left(\varphi_{r h q}^{j}\right)_{n \times n}$. To reflect decision-makers' preference to the housing, combined with the location $\varphi_{r h q}^{j}$ and weight $\tilde{w}_{q}^{j}$ of all target corresponding for the community $d_{r}$, and make a comprehensive summation, get the comprehensive ranking matrix $\widetilde{B}^{j}=\left(\tilde{b}_{m}^{j}\right)_{n n}$ of the community $d_{r}$, here:

$$
\tilde{b}_{m}^{j}=\sum_{q=1}^{m_{s}} \varphi_{m q}^{j} \underset{w_{q}^{j}}{\sim} \quad r=1,2, \cdots n, h=1,2, \cdots, n
$$

And, $\tilde{b}_{r h}^{j}$ is the comprehensive weights that decision makers $j$ give the community $d_{r}$, the more ,the better. ${ }^{\simeq}{ }^{j}$ is the fuzzy weighted.

According to (3), apply the Borda function, calculating the Borda choose function value of each residential area $d_{r}(r=1,2, \mathrm{~L}, n)$ given by the family decision makers $j(j \in F)$. The model is:

$$
B^{j}\left(d_{r}\right)=\sum_{t=1}^{n}(\mathrm{n}-\mathrm{t}) \stackrel{\text { o }}{\text { r }}
$$

Where $n$ is the total number of the alternative housing. Denote the Borda choose function value of each residence district given by the same attribute decision-making group as: 


$$
B\left(d_{r}\right)=\sum_{j=1}^{e} B^{j}\left(d_{r}\right)
$$

Where $e$ is the number of decision makers for the same attributes.

Compare the Borda function values and get the optimal residence for decision makers.

\section{Example}

Take the main city of Nanchang as the research object. Combined with the characteristics of the road network, Nanchang City will be divided into 25 residential areas, as shown in the figure1.And district 4, 15 are the downtown areas. People have seven major commuter destinations, they are district 2, 4, 9 , $15,17,18,22$. And district 1, 14, 16, 21, 23, 24 contain a park, residence 1 and 16 are the holiday leisure places, there are shopping malls in district 4,10,15, 19and key primary and secondary schools in district $3,10,13,15,20,21$.

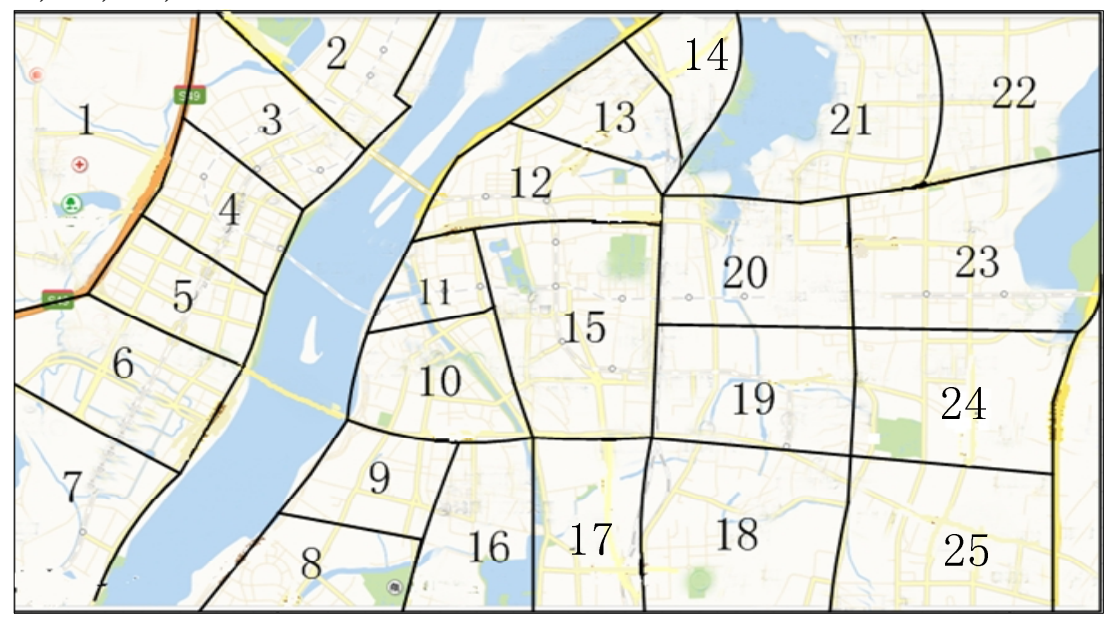

Fig1: District Division Figure of The Study Area

And as shown in the figure 1, there is a two-way road connection between adjacent residential area, the capacity of each other in the opposite direction and the free- flow speed of each road are the same, The width of the independent non-motor vehicle lane is 3 meters. The capacity of the main road is $7000 \mathrm{veh} \bullet \mathrm{h}-1$ and free-flow speed is $70 \mathrm{~km} \bullet \mathrm{h}-1$. The capacity of the Level 1 street is $5500 \mathrm{veh} \cdot \mathrm{h}-1$ and free-flow speed is $50 \mathrm{~km} \bullet \mathrm{h}-1$. The capacity of the Secondary street is $4000 \mathrm{veh} \bullet \mathrm{h}-1$ and free-flow speed is $40 \mathrm{~km} \bullet \mathrm{h}-1$.

Fig.2: Triangular Fuzzy Number

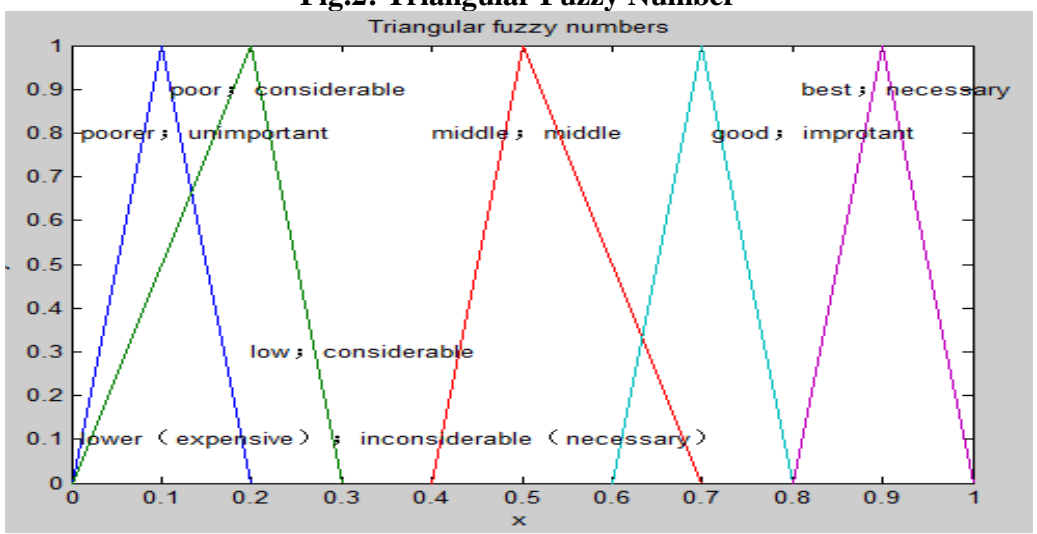


Table1: Preferences of Residents with Different Attributes When Choosing To Live

\begin{tabular}{|l|l|l|l|l|l|l|l|l|}
\multicolumn{2}{|c}{} & completeness & $\begin{array}{l}\text { population } \\
\text { density }\end{array}$ & environment & transportation & $\begin{array}{l}\text { housing } \\
\text { price }\end{array}$ & entertainment & education \\
\hline \multirow{4}{*}{$\begin{array}{l}\text { Age } \\
\text { groups }\end{array}$} & $23 \sim 30$ & important & important & important & $\begin{array}{l}\text { very } \\
\text { important }\end{array}$ & $\begin{array}{l}\text { very } \\
\text { important }\end{array}$ & $\begin{array}{l}\text { very } \\
\text { important }\end{array}$ & important \\
\cline { 2 - 8 } & $31 \sim 45$ & $\begin{array}{l}\text { More } \\
\text { important }\end{array}$ & $\begin{array}{l}\text { More } \\
\text { important }\end{array}$ & $\begin{array}{l}\text { very } \\
\text { important }\end{array}$ & important & important & considerable & necessary \\
\cline { 2 - 8 } & $46 \sim 59$ & very important & important & $\begin{array}{l}\text { very } \\
\text { important }\end{array}$ & considerable & important & so-so & important \\
\hline \multirow{3}{*}{$\begin{array}{l}\text { Income } \\
\text { level }\end{array}$} & low & imconsiderable & imconsiderable & considerable & $\begin{array}{l}\text { More } \\
\text { important }\end{array}$ & necessary & unimportant & important \\
\cline { 2 - 9 } & middle & important & important & important & $\begin{array}{l}\text { More } \\
\text { important }\end{array}$ & $\begin{array}{l}\text { More } \\
\text { important }\end{array}$ & important & necessary \\
\cline { 2 - 9 } & high & necessary & $\begin{array}{l}\text { More } \\
\text { important }\end{array}$ & necessary & unimportant & unimportant & necessary & necessary \\
\hline
\end{tabular}

\begin{tabular}{|c|c|c|c|c|c|c|c|c|c|c|c|c|c|}
\hline community & 1 & 2 & 3 & 4 & 5 & 6 & 7 & 8 & 9 & 10 & 11 & 12 & 13 \\
\hline Completeness & better & good & better & best & better & better & good & well & good & best & good & good & good \\
\hline $\begin{array}{l}\text { population } \\
\text { density }\end{array}$ & good & good & good & $50-50$ & good & good & good & well & well & $50-50$ & well & $50-50$ & middle \\
\hline environment & good & better & better & best & better & better & good & andale & midale & good & midale & $80-50$ & poorest \\
\hline transportation & good & good & good & best & better & better & middie & 50-50 & good & good & good & midale & good \\
\hline public secuity & better & better & better & best & best & better & better & anidale & best & best & middle & middile & $50-50$ \\
\hline housing price & costly & costly & expensive & dear & costly & costly & costly & anidale & expensive & expensive & costly & costly & costly \\
\hline entertainment & better & $50-50$ & good & best & middle & middle & $50-50$ & $50-50$ & 80-50 & good & good & good & middle \\
\hline education & $80-50$ & $80-50$ & best & good & good & middle & $50-50$ & $50-50$ & middle & best & middie & $50-50$ & best \\
\hline community & 14 & 15 & 16 & 17 & 18 & 19 & 20 & 21 & 22 & 23 & 24 & 25 & \\
\hline completeness & good & better & good & good & middle & good & middle & $50-50$ & good & good & $50-50$ & poor & \\
\hline $\begin{array}{l}\text { population } \\
\text { density }\end{array}$ & 80-50 & pooler & middle & well & $50-50$ & $50-50$ & middie & $50-50$ & better & middle & good & good & \\
\hline environment & better & middie & good & $50-50$ & poorest & middle & $80-50$ & good & better & good & good & $50-50$ & \\
\hline transportation & middle & best & middle & good & $80-50$ & $50-50$ & middle & poor & good & middle & midale & $50-50$ & \\
\hline public secuity & $50-50$ & middle & good & $50-50$ & middle & better & $50-50$ & good & aridale & $50-50$ & $50-50$ & middle & \\
\hline housing price & costly & $\begin{array}{l}\text { expensi } \\
\text { ve }\end{array}$ & midale & middle & cheag & low & low & midale & costly & costly & midale & low & \\
\hline entertainment & good & best & good & $80-50$ & poorer & good & pool & good & middle & $50-50$ & $50-50$ & 80-50 & \\
\hline education & midale & best & $50-50$ & $50-50$ & poor & poor & best & best & middle & $50-50$ & poor & poor & \\
\hline
\end{tabular}

According to the semantics evaluation of each area and the corresponding relationship between fuzzy evaluation, as shown in the table1, table2and figure 2, simulation model by MATLAB, we can get the following results of the best places to live in choice of family with different ages.

Table3: The Results of Low- income Residents from 23 to 30 Years Old Choose To Live

\begin{tabular}{|c|c|c|c|c|c|c|c|c|}
\hline Age groups & Destination & 2 & 4 & 9 & 15 & 17 & 18 & 22 \\
\hline \multirow{2}{*}{$23 \sim 30$} & $\begin{array}{c}\text { The number of } \\
\text { low-income families }\end{array}$ & 844 & 914 & 1123 & 2256 & 1149 & 3585 & 3654 \\
\hline & Result of selection & 2 & 4 & 9 & 15 & 17 & 18 & 22 \\
\hline Age groups & Destination & 2,4 & 4,9 & 9,15 & 15,17 & 17,18 & 18,22 & \\
\hline \multirow[t]{2}{*}{$23 \sim 30$} & $\begin{array}{l}\text { The number of } \\
\text { low-income families }\end{array}$ & 923 & 1003 & 1158 & 1231 & 2232 & 3492 & \\
\hline & Result of selection & 2 & 9 & 9 & 17 & 19 & 24 & \\
\hline \multicolumn{9}{|c|}{ Table4: The Results of Low- income Residents from 31 to 45 Years Old Choose To Live } \\
\hline Age groups & Destination & 2 & 4 & 9 & 15 & 17 & 18 & 22 \\
\hline \multirow{2}{*}{$31 \sim 45$} & $\begin{array}{c}\text { The number of } \\
\text { low-income families }\end{array}$ & 844 & 914 & 1123 & 2256 & 1149 & 3585 & 3654 \\
\hline & Result of selection & 3 & 3 & 9 & 15 & 16 & 20 & 21 \\
\hline Age groups & Destination & 2,4 & 4,9 & 9,15 & 15,17 & 17,18 & 18,22 & \\
\hline \multirow[t]{2}{*}{$31 \sim 45$} & $\begin{array}{c}\text { The number of } \\
\text { low-income families }\end{array}$ & 923 & 1003 & 1158 & 1231 & 2232 & 3492 & \\
\hline & Result of selection & 3 & 9 & 10 & 20 & 20 & 20 & \\
\hline \multicolumn{9}{|c|}{ Table5: The Results of Low- income Residents from 46 to 59 Years Old Choose To Live } \\
\hline Age groups & Destination & 2 & 4 & 9 & 15 & 17 & 18 & 22 \\
\hline \multirow[t]{2}{*}{$46 \sim 59$} & $\begin{array}{l}\text { The number of } \\
\text { low-income families }\end{array}$ & 844 & 914 & 1123 & 2256 & 1149 & 3585 & 3654 \\
\hline & Result of selection & 2 & 1 & 9 & 16 & 17 & 18 & 22 \\
\hline Age groups & Destination & 2,4 & 4,9 & 9,15 & 15,17 & 17,18 & 18,22 & \\
\hline \multirow[t]{2}{*}{$46 \sim 59$} & $\begin{array}{c}\text { The number of } \\
\text { low-income families }\end{array}$ & 923 & 1003 & 1158 & 1231 & 2232 & 3492 & \\
\hline & Result of selection & 2 & 9 & 16 & 17 & 18 & 24 & \\
\hline
\end{tabular}


As shown in the table3, table 4, and table 5, the living location choice of residents with different age and income levels and the demand for living location factors are different. Residents from 23 to 30 years old belong to the preference for the life, they pay more attention to the entertainment environment and the employment environment. Residents with the lower income and age levels as much as possible will be choose the district that close to commuter destination, have lower prices and good entertainment environment. Residents from 31 to 45 years old also belong to the lifestyle, but most of them have children, they pay more attention to the surrounding educational environment. Residents with lower income levels, the choice of residence can only be based on education environmental, they will choose the district that have good education environment and lower prices. Residents from 46 to 59 years old, belong to the preference for ecological, emphasize more on natural and humanistic greening environment around residential location. Low income families in these ages, usually tend to choose districts that are cheap, close to parks and have good natural and humanistic greening environment. Therefore, in the process of urban planning, the government and real estate developers should earnestly consider the different needs of residents with different attributes. In order to enhance the overall urban geographical advantages, they should be targeted to improve the residential location.

\section{Conclusions}

This article was based on the behavior characteristic of residence and concerned multi-objective attributes selections according to the different properties of residents, using fuzzy method to get the fuzzy evaluation of the location target. And a fuzzy multi-objective ranking model based on the residents' attributes was constructed to explore the process of residential selection. We can get the residential location and closeness degree of the target by fuzzy membership function. Synthesized the close degree and weight of the location object and we used Borda choice function to select out the residence where has the maximum satisfaction for different residents with different attributes. By means of fuzzy method, the decision-making process of people in residential selection was simulated, which can reflect human's thinking process. The model can provide the basis for the optimization of urban residential location structure and the purchase policy strategy. The next step is to explore the choice of the residence which contains the rail transit based on the fuzzy multi-objective and multi-person decision making.

\section{Acknowledgements}

This research is supported by National Natural Science Foundation of China under Grant No. 51368046 and Natural Science Foundation of Jiangxi Province of China under Grant No. $20151 \mathrm{BAB} 201028$.

\section{References}

[1] Abdul R P, Chandra R B, David A H. Residential self-selection effects in an activity time-use behavior model [J]. Transportation Research Part B, 2009(3), 43:729-748.

[2] Meloni I, Spissu E, Bez M. A model of the dynamic process of time allocation to discretionary activities[J]. Transportation Science, 2007, 41(1):15-28.

[3] Khattak A.J, Rodriguez D. Travel behavior in neo-traditional neighborhood developments:a case study in USA[J]. Transportation Research Part A, 2005, 39(6):481-500. 